\title{
Optimization of Production Operation Scheme in the Transportation Process of Different Proportions of Commingled Crude Oil
}

\author{
Kai Yang ${ }^{1,3, *}$ and Yuwei Liu ${ }^{2}$ \\ ${ }^{1}$ Daqing Oilfield No. 2 Oil Production Plant, Daqing, Heilongjiang, 163000, China \\ ${ }^{2}$ University of Science and Technology Beijing, Beijing, 100083, China \\ ${ }^{3}$ Department of Petroleum Engineering, Curtin University, 6845, Australia
}

Received 12 August 2017; Accepted 21 December 2017

\begin{abstract}
At present, the mixed transportation technology of different kinds of crude oil is widely used in long-distance pipeline transportation process. The energy consumption produced by pipeline at different monthly temperatures varies because the physical properties of crude oil mixed with different mixing ratios are unique. However, the industry often only formulates the mixed crude oil transportation scheme according to the fixed mixing ratio, thereby resulting in high energy consumption of the pipeline system transporting the commingled crude oil. The optimized mathematical model under the mixing transportation conditions of different mixing proportions of oils was established to minimize the energy consumption in the operation of commingled crude oil and minimize the overall operating costs. Different blending ratios of transporting commingled crude oil, operation scheme of related energy consumption equipment, and temperature and pressure parameters of outgoing station were optimized. The optimization scheme for oil transportation of different mixing proportions in the typical case was determined in the study. Results demonstrate that the number of heating furnaces required for operation e is reduced after the optimization, and the number of heating days also decreased by 16 days. The ex-station pressure of each oil transportation station slightly increases, but the ex-station temperature is evidently reduced. The electricity consumption increases by $103,169 \mathrm{KWh}$, and the total fuel oil consumption decreases by 155.6 t. Compared with the situation before optimization, the total energy consumption cost of crude oil transportation is reduced by RMB 437,500 , thereby saving $26.28 \%$. By optimizing the production and operation plan of the mixed proportion of crude oil transported in different months, the cost of pipeline transportation is considerably reduced, and the economic benefit of pipeline operation is enhanced. This study provides technical support for the optimization of the actual operation and production scheme on the oil pipeline site to an extent and may ensure the economical and stable operation of the pipeline in case of varying transportation proportions.
\end{abstract}

Keywords: Oil pipeline, Blending ratio, Optimizing operation, Energy consumption

\section{Introduction}

The production and operation optimization of oil pipeline requires formulating a reasonable oil transportation plan and operation scheme when the basic pipeline parameters, oil transportation equipment in each oil transportation station, system process, and surrounding environmental conditions have been determined to minimize the energy costs consumed by the throughput within the specified time. A considerable amount of energy is needed during the production and operation of long-distance oil pipeline. The energy costs come from the heating and power costs. Owing to the high viscosity and easy solidification characteristics of crude oil, transporting crude oil after heating is generally adopted, and this process is mainly achieved through burning fuel oils in the heating furnace. The heating costs are produced from the pipeline operation. The power costs come from the electricity cost of the centrifugal pump. In general, a high crude oil heating temperature in the pipeline leads to high heating costs and a low-pressure requirement

\footnotetext{
*E-mail address: yangkai2012@sina.com

ISSN: 1791-2377@ 2017 Eastern Macedonia and Thrace Institute of Technology. All rights reserved. doi:10.25103/jestr.106.22
}

for crude oil transportation from the first to the last station results in low power costs. Conversely, low heating costs lead to high power costs. Hence, the problem that must be solved in the production optimization of oil pipeline is finding a set of reasonable ex-station temperature and pressure in each oil transportation station to minimize the sum of power and heating costs. At present, the optimized mathematical model for the production and operation scheme of oil pipeline mainly optimizes the equipment combination and operating parameters.

However, with the rapid growth of the global economy, the demand for energy has substantially increased. Simultaneously, the domestic crude oil production in China is decreasing yearly. The proportion of imported crude oil in the petroleum energy consumption of China has gradually increased to ensure a steady and sustainable supply. At present, one of the technical issues in crude oil transportation process in China is proportionally mixing domestic and imported crude oil. Optimizing the transportation scheme in certain periods is possible due to the physical differences of crude oil with different mixing proportions and the discretization of oil transportation time and equipment combination scheme, combined with the constant changes of surrounding soil temperature with different seasons and months. Currently, most theoretical 
studies considered a kind of or fixed proportion of commingled crude oil [1-3]. Adjusting the adaptability of the mixed crude oil transportation scheme according to the oil transport environment in different months is difficult. If the same mixing proportion is used to transport oil in different seasons, then the energy consumption and pipeline operating costs will increase and seriously influence the economic benefits of the pipeline operation. Therefore, on the basis of not changing the pipeline transportation process equipment, the safe and smooth transportation of crude oil mixed in a certain proportion to the designated place and minimization of energy consumption in pipeline transportation must be addressed in the transportation process of long-distance hot oil mixing and transportation pipeline.

Based on the preceding analysis, considering the optimization of equipment combination and operating parameters, this study established the optimization model through the following steps: taking the oil transportation proportion and oil transportation time corresponding to the mixing proportion as the decision variables, optimizing the oil transportation proportion scheme in the transportation process of commingled crude oil, reasonably adjusting the production and scheduling scheme for commingled crude oil, and providing the production and operation scheme with minimum energy consumption for the transportation of different mixing proportions of oil.

\section{State of the art}

The studies on pipeline optimization operation began in the 1950 s with the increase in pipeline transportation proportion in oil delivery. Kiernikin, a scholar of the former Soviet Union, pioneered the optimal heating temperature of the pipeline. The open process was the primary method used at that time because the pump that supplies pressure to the pump station was the reciprocating pump. The crude oil in the pipeline can be regarded as a Newton fluid, and the relationship between the optimum outstation temperature and other parameters can be deduced by differential theory. This theory is the basis for the optimization and operation of hot oil conveying pipeline. As the research progressively deepened, the studies on the optimization model gradually changed from the pump pipeline decoupling and single station-to-station calculation to pump pipe coupling and calculation system model of pipe section between different stations on the entire line to obtain study results approximate to the actual production. The optimization scope also expanded from the second-order phase to the optimization of all-line pump, heating furnace and other equipment, and operating parameters.

The pipeline transportation process has a long history abroad; hence, it was early in the study of pipeline optimization. Gefferson [4] and others investigated pressure head distribution in each station and crude oil transportation in certain throughput by the pipeline. The dynamic programming method was used to solve it because the pressure of each pump station is different. Finally, the optimal distribution scheme of the head between stations was obtained, and the minimum energy consumption under isothermal conditions was calculated. Vijerden N. G. and others selected the opening conditions of pump according to the dynamic energy consumption function of each pump and assembled the opening conditions of all pumps to the optimal scheme of the entire pipeline operation [5]. PE Company in Germany designed and prepared the software program on the optimal operation scheme of crude oil and refined oil pipeline. Satisfactory results have been achieved in the optimization of many oil pipelines in Europe [6]. Nguyen and Hanh H. [7] researched the combinatorial optimization of equipment in the scheduling scheme according to the genetic algorithm. The actual production consumption after the optimization suggested apparent optimization results. Afshar, M. H. and others selected appropriate variables in the pipeline optimization process, solved the problems with genetic algorithm, and improved the searching speed of the optimal solution. Chebouba, A. [9] and others optimized the pipeline with ant colony algorithm and carried out the optimization calculation with the opening conditions of the equipment as the decision variable and the minimum energy consumption as the target. Their obtained optimization results are very ideal. Sun F. F. and others researched the optimized operation of low-flow pipelines, determined the minimum pump flow by experiments, researched the motor and pump mismatch, improper pump selection, saving flow and energy losses, summarized the reasonable pump flow, and ensured the optimized operation of the pipeline [10]. Compared with domestic crude oil, imported crude oil possesses good fluidity and can be transported at constant temperature. The optimization method of domestic crude oil will vary compared with that of foreign pipeline due to "three high" (high condensation, high viscosity, and high wax content) characteristics of domestic crude oil. In addition to pressure optimization, temperature should be optimized in the process of hot oil pipeline optimization.

The domestic studies on the optimization of oil pipeline started late. Wu Changchun, Sun Qingfeng, and others [11] applied the two-order hierarchical optimization model of single pipeline in the double-pipeline system. According to the technological process of production and operation, the optimization model of oil transportation temperature was solved by the coordinate rotation method. The optimal matching model of pump pipeline in the second layer was solved by the dynamic programming method. Starting with the investigation and study on the historical parameters of pipeline operation, Li Yuchun adjusted the operation scheme of inter-station pipe segment group after the analysis and provided the safe and reasonable measures combined with the study on pipeline operation risk [12]. Chen Youwang and others developed a system platform for calculating and analyzing energy consumption of crude oil pipeline centering on the steady-state optimization calculation model and software programming under certain flow rate. The optimal oil transportation scheme was determined by optimizing the oil transportation capacity of each month. The practical example shows that the optimized system can effectively optimize the oil transportation temperature and reduce the heating costs [13]. Sun Fafeng conducted an optimization study on energy-saving and emission-reduction of the western pipelines and proposed the corrective plan to reduce the pipeline energy consumption and environmental pollution. Consequently, the pipeline operation consumption the operating costs were reduced [14]. Li Haina and others established the mathematical model of pump combination optimization under time-sharing tariff system of peak and valley and obtained the optimal pump combination and oil transportation scheme for the average and dayparting throughput. They simultaneously analyzed the unit energy consumption in the transportation process of different mixing proportions of crude oil and suggested that the energy saving effect for transporting oils is different with 
varying mixing proportions [15]. Wei Lixin and others established the simulation model, which simulates the operation state of pipeline under different working conditions with TLNET simulation software, and optimized the pipeline operation parameters in different seasons to save energy and reduce consumption [16]. Yu Yang and others established the mathematical model of optimal operation and energy consumption of pipeline according to the pipeline topology, process flow, and operating principle and proposed the combination of three energy-saving measures with the engineering practice: reducing oil temperature, matching peak and valley price, and combining with traffic during the planned operation period [17]. W. Yuguo and others established the mathematical model for the optimal operation of super heavy oil pipeline and investigated the optimal operation of heavy oil heating pipeline in Liaohe Oilfield based on the study on rheological properties, viscosity and temperature characteristics of super heavy oil pipeline, thermodynamic calculation, and hydraulic calculation. The operating costs have been evidently reduced after operating parameter optimization [18].

The existing study shows that many studies by domestic and foreign scholars currently focus on pipeline optimization However, the following shortcomings are present. First, the rheological properties of crude oil with different blending ratios are different in the transport medium. Only a few studies discuss the transportation ratio of commingled crude oil. Second, the enumeration method in the combinatorial optimization is adopted for most combinatorial optimization problems at present. However, the efficiency of the enumeration method cannot meet the actual requirements with the increase in mixing proportion types and the number of site equipment. A few studies focus on improving the optimization efficiency of the optimal oil transportation scheme with ant colony algorithm.

Addressing the shortcomings of existing research, this study selects the commingled crude oil mixed by Russian crude oil and Daqing crude oil in 1:1, 1:2, 1:3, 1:4, and 0:1 (pure Daqing oil) as the research objects and regards the proportion of transporting commingled crude oil and the corresponding oil transportation time as one of the decision variables. The present study establishes the optimized mathematical model for the production and operation scheme of oil pipeline under the mixing transportation conditions and optimizes the scheduling program of crude oil transportation proportion, equipment combination opening scheme, and operation parameter scheme with ant colony algorithm. This study also determines the production and operation scheme with the lowest energy consumption expenses in the commingled crude oil transportation process under the conditions of given transmission, temperature, and mixing proportion.

The remainder of this study is organized as follows. Section 3 establishes the optimized mathematical model according to the operation process of Daqing-Harbin oil pipeline and provides the solution algorithm according to the model structure characteristics. Section 4 optimizes the typical production and operation scheme and analyzes the optimization results. The last section summarizes this study and provides the relevant conclusions.

\section{Methodology}

\subsection{Establishment of optimized mathematical model}

The optimization of operation scheme under the mixing transportation conditions of Daqing-Harbin oil pipeline mainly refers to the establishment of the optimized mathematical model for the production and operation scheme. This model takes the oil transportation proportion, oil transportation time, combination scheme of oil transportation pump, heating furnace and other equipment, oil transportation temperature, and pressure as the decision variables. Considering the various safety operating parameters and guaranteeing the temperature and pressure of the final station, this model aims to minimize the overall energy consumption on the premise of addressing the transportation tasks:

$$
\begin{aligned}
& \min F\left(\alpha, \tau_{\alpha}, \delta, \gamma, P_{R}, T_{R}\right)=\sum_{i=1}^{N_{x}}\left(e_{p} W_{i} \tau_{i}+e_{f} B_{i} \tau_{i}\right) \\
& W=\sum_{j=1}^{N_{s}} \sum_{k=1}^{N_{\mathrm{p}, j}} \delta_{p j, k} \cdot \frac{\rho_{\mathrm{h}} g q_{\mathrm{p} j, k}\left[a_{j, k}\left(\frac{n_{j, k}}{n_{0 j, k}}\right)^{2}-b_{i, j}\left(\frac{n_{j, k}}{n_{0 j, k}}\right)^{2-m} q_{\mathrm{p} j, k}^{2-m}\right]}{1000 \eta_{\mathrm{p} i, j} \eta_{\mathrm{e} i, j}} \\
& B=\sum_{j=1}^{N_{\mathrm{s}}} \sum_{k=1}^{N_{f, j}} \gamma_{f j, k} \cdot \frac{c_{\mathrm{h}} q_{\mathrm{f} j, k} \rho_{\mathrm{h}}\left(T_{\mathrm{fout}, k}-T_{\mathrm{finj}, k}\right)}{Q_{\mathrm{r}} \eta_{\mathrm{fj}, k}}
\end{aligned}
$$

$$
\text { s.t: }
$$$$
\sum_{k=1}^{N_{\mathrm{p}, j}}
$$$$
\sum_{k=1}^{N_{\mathrm{p}, j}} \delta_{j, k} \cdot q_{\mathrm{p} j, k} \cdot t_{\mathrm{z}}=Q_{\mathrm{z}}, \forall j \in \mathrm{S}_{\mathrm{S}}
$$

$$
\sum_{k=1}^{N_{\mathrm{f}, j}} \gamma_{j, k} \cdot q_{\mathrm{f} j, k} \cdot t_{\mathrm{z}}=Q_{\mathrm{z}}, \forall j \in \mathrm{S}_{\mathrm{S}}
$$

$$
\sum_{i=1}^{N_{x}} q_{i} \tau_{i}=Q_{z}=Q_{q}+Q_{e}
$$$$
\sum_{i=1}^{N_{x}} \tau_{i}=t_{z}
$$

$Q_{i} \geq\left[G_{\min }\right]_{\tau_{i}}$

$n_{j, k}^{\min } \leq n_{j, k} \leq n_{j, k}^{\max }, k=1, \ldots, N_{p, i}, \forall j \in \mathrm{S}_{\mathrm{S}}$

$$
Q_{\mathrm{f}, k}^{\min } \leq Q_{\mathrm{fj}, k} \leq Q_{\mathrm{fj}, k}^{\max }
$$

$T_{i n, i, j} \geq T_{\min }, \forall j \in \mathrm{S}_{\mathrm{S}}$

$$
T_{\text {out }, i, j} \leq T_{\max }, \forall j \in \mathrm{S}_{\mathrm{S}}
$$

$P_{\text {out }, i, j} \leq\left[\mathrm{P}_{\max , i, j}\right], \forall j \in \mathrm{S}_{\mathrm{S}}$

$$
P_{\text {out }, i, j} \geq 10^{-6} \cdot \rho_{h} g\left(h_{\mathrm{f}, i, j}+h_{\xi, i, j}+\Delta Z_{i, j}\right)+P_{\min , i, j}, \forall j \in \mathrm{S}_{\mathrm{S}}
$$

where $\alpha$ is the vector of mixing proportion; $\tau_{\alpha}$ is the time vector of transporting $\alpha$ mixing oil; $\delta$ is the vector of pump operation status; $\gamma$ is the operation status vector of heating 
furnace; $P_{R}$ is the vector of ex-station pressure; $T_{R}$ is the vector of ex-station temperature; $F$ is the overall energy consumption; $e_{f}$ is the unit price of fuel; $e_{p}$ is the unit price of electricity; $N_{x}$ is the type of proportion of transporting mixing oil; $B_{i}$ and $W_{i}$ are the oil and power consumption when transporting $i$ proportion of crude oil in the unit time, respectively; $\tau_{i}$ is the time when transporting $i$ proportion of crude oil; $N_{s}$ is the total number of oil transportation stations; $N_{\mathrm{p}, j}$ is the total number of $j$ station pumps; $N_{\mathrm{f}, j}$ is the total number of the $j$ station heating furnaces; $\delta_{p, j, k}$ is the operation status of $j$ pump; $\gamma_{f, j, k}$ is the $j$ operation status of $k$ heating furnace; $q_{\mathrm{p} j, k}, a_{j, k} 、 b_{j, k}, n_{0 j, k}, n_{j, k}$, $n_{j, k}^{\max }, n_{j, k}^{\min }, \eta_{\mathrm{p} j, k}$, and $\eta_{\mathrm{e} j, k}$ are the actual throughput, characteristic parameters, rated speed, actual speed, maximum and minimum speed, pump efficiency, and $k$ pump motor efficiency of $j$ station, respectively; $\rho_{\mathrm{h}}$ and $c_{\mathrm{h}}$ are the density and specific heat capacity of commingled crude oil, respectively; $q_{\mathrm{f} j, k}, T_{\mathrm{fin} j, k}, T_{\mathrm{fout} j, k}, \eta_{\mathrm{fj}, k}, Q_{\mathrm{f} j, k}^{\max }$, and $Q_{\mathrm{f} j, k}^{\min }$ are the crude oil flow, import and export oil temperature, thermal efficiency, maximum and minimum thermal load of $k$ heating furnace of $j$ station, respectively; $t_{z}$ is the total scheduling time; $Q_{\mathrm{p}}$ is the total throughout; $q_{i}$ is the flow when transporting $i$ type of mixed proportion crude oil; $Q_{q}$ is the total quantity of Daqing crude oil before mixing; $Q_{e}$ is the total quantity of Russian crude oil before mixing; $\left[G_{\min }\right]_{\tau_{i}}$ and $Q_{i}$ are the lowest throughput and the total throughput when transporting $i$ type of mixed proportion crude oil, respectively; $T_{\min }$ is the allowable lowest in-station oil temperature; $T_{\max }$ is the highest exstation oil temperature; $T_{i n, i, j}$ and $T_{\text {out }, i, j}$ are the temperature of $i$ type of mixed proportion crude oil going in and out of the $j$ station, respectively; $P_{\text {out }, i, j}, H_{\mathrm{f}, i, j} H_{\xi, i, j}, \Delta Z_{i, j}$, $P_{\min , i, j}$, and $\left[\mathrm{P}_{\max , i, j}\right]$ are the starting pressure, friction loss, local friction loss, elevation difference between the first and final station, the lowest in-station pressure and the highest ex-station pressure in the corresponding pipe sections in $j$ station when transporting $i$ type of mixed proportion crude oil, respectively. Equations (4)-(14) are constraints, namely, throughout, oil transportation pump working performance, heating furnace heating capacity, oil pipeline end-point temperature, oil transportation station ex-station temperature, and oil transportation station ex-station pressure.

\subsection{Solution algorithm for optimized mathematical model}

In the optimization of Daqing-Harbin oil pipeline commingled crude oil transportation scheme, decision variables, such as the proportion of commingled crude oil, transportation time of the proportion of crude oil, and opening-closing status of pump and heating furnace are discrete variables, whereas the ex-station temperature and ex-station pressure in each oil transportation station are the continuous variables. Therefore, the optimization of
Daqing-Harbin oil pipeline commingled crude oil transportation scheme belongs to the optimal design of mixed variables. The problem becomes a nonlinear optimization problem because the nonlinear items are included in the target function and constraints. Hence, directly solving this kind of problem is very difficult. According to the characteristics of the model, the solution process can be divided into two levels. The first level determines the oil transportation proportion schedule and equipment combination scheme, namely, the commingled crude oil transportation proportion, transportation time under the proportion, and opening scheme of corresponding pumps and heating furnace. After ascertaining the oil transportation proportion schedule and oil transportation combination scheme at the second level, the operating parameters of exstation temperature and pressure may be determined. The iterative solution is needed for this process because the parameter optimization and the optimization of equipment combination scheme are coupled with each other.

\subsubsection{Optimization of oil transportation proportion} scheme and equipment operation scheme

Oil transportation proportion scheme is the optimization of transportation proportion and transportation time under the proportion. The optimization of the equipment operation scheme finds the best combination of heating furnace and pump under certain oil transportation proportion schedules. The combination optimization refers to determining a kind of oil transportation proportion schedule and corresponding equipment opening scheme with the minimum energy consumption in the planned oil transportation cycle after the optimization of equipment operation scheme. The commonly used method is enumeration. The combination mode increases with the increase in mixing proportion, the number of site equipment, and the general scheduling. The enumeration method clearly cannot meet the needs. This paper uses ant colony algorithm for solutions to improve the efficiency of the search.

Regarding the oil pipeline which has been built and put into operation, the specific model and quantity of station pump and heating furnace are certain. The mode of each type of pump in series and parallel is also fixed. Therefore, the opening and closing of different pumps and heating furnaces formed the equipment combination mode of the oil transportation station. Regarding the optimal combination of pipeline equipment under certain oil transportation proportion schedule, each set of equipment (pump, heating furnace) can be regarded as a city. The equipment start-up (1 indicates start-up) and shutdown (0 indicates shutdown) represent two channels to the city. Ants are faced with two choices when they reach the urban node of each device. Opening or closing one device corresponds to certain mixing proportion and oil transportation time. The different combinations of equipment shutdown or startup mean one combination channel. Regarding the optimization issue of the scheduling program of crude oil transportation proportion, relationships between the crude oil transportation time and corresponding crude oil amount under different mixing proportions of transportation scheduling programs can be generated as per the constraint of transportation amount. Owing to the discretization of the crude oil transportation proportion and the transportation time, the two can be deemed as one city, and the selected route is the crude oil transportation proportion and the transportation time. Thus, when one ant completes the journey of $\mathrm{n}$ cities, an entire route will be generated, namely, a feasible solution 
of one kind of equipment combination of the entire pipeline under one proportion scheduling program.

Under the initial condition, if the information element on each route is set as one constant, then the information elements are updated and the total energy consumption $\mathrm{F}$ forms one relation when one ant completes the journey of all the $\mathrm{n}$ cities. A large total energy consumption results in less accumulated information elements. Conversely, additional accumulated information elements will be produced. After iteration times, an optimal route with the least energy consumption will be obtained.

The increment of the information element can be set as $\Delta \tau=\frac{k \tau}{F}$, and the formula of updated information element is as follows:

$$
\tau_{i}=\tau_{i-1}+\frac{k \tau_{i-1}}{F}
$$

where $\tau_{i}$ is the current information element, $\tau_{i-1}$ is the last time of information element, $\frac{k \tau_{i-1}}{F}$ is the updated amount of information element, $F$ is the total energy consumption, and $K$ is the coefficient.

\subsubsection{Operational parameter optimization}

When pipeline operational parameter optimization is carried out, the temperature of crude oil transportation shall first be confirmed, and pressure optimization can then be carried out under the certain thermal condition. During the solution process, the pressure variant is first disposed and the direct method is then applied in the nonlinear programming method to find the solution. Owing to the constraint of the crude oil temperature in the optimization issue, the penalty function method is first adopted in the solving process to convert the constraint into an unconstrained nonlinear optimization issue. The Powell direction acceleration method is then adopted to find the solution. The expression form of the penalty function is as follows:

$$
\begin{aligned}
& D\left(\mathrm{~T}_{\text {out }}\right)=F\left(\mathrm{~T}_{\text {out }}\right)+M_{k}\left(f_{1}+f_{2}\right) \\
& f_{1}=\left[\max \left(T_{\text {out }}-T_{\text {out,max }}, 0\right)\right]^{2} \\
& f_{2}=\left[\max \left(T_{\text {out,min }}-T_{\text {out }}, 0\right)\right]^{2}
\end{aligned}
$$

where $M_{k}$ is the penalty factor.

\subsubsection{General solving process of optimization}

The preceding analysis shows that the general solving thought of optimization can be summarized as follows: According to the constraint of transportation amount, the relationship between the crude oil transportation time and transportation amount under different mixing ratios of transportation scheduling program can be confirmed. The ant colony algorithm can be adapted to optimize the crude oil transportation ratio scheduling program and the starting program of equipment at each station. One entire route for each ant as per the probabilistic transition rules is confirmed, this route is one of the equipment combination programs under a kind of mixing ratio transportation program. The pipeline operation parameters are optimized to confirm the optimal operational parameters under the combination program, thereby calculating the corresponding objective function value. The information elements are updated on the route as per the information element update formula to finally achieve the maximum power of iteration. The optimal solution of the issue is thereafter obtained. The procedure of calculation is as follows:

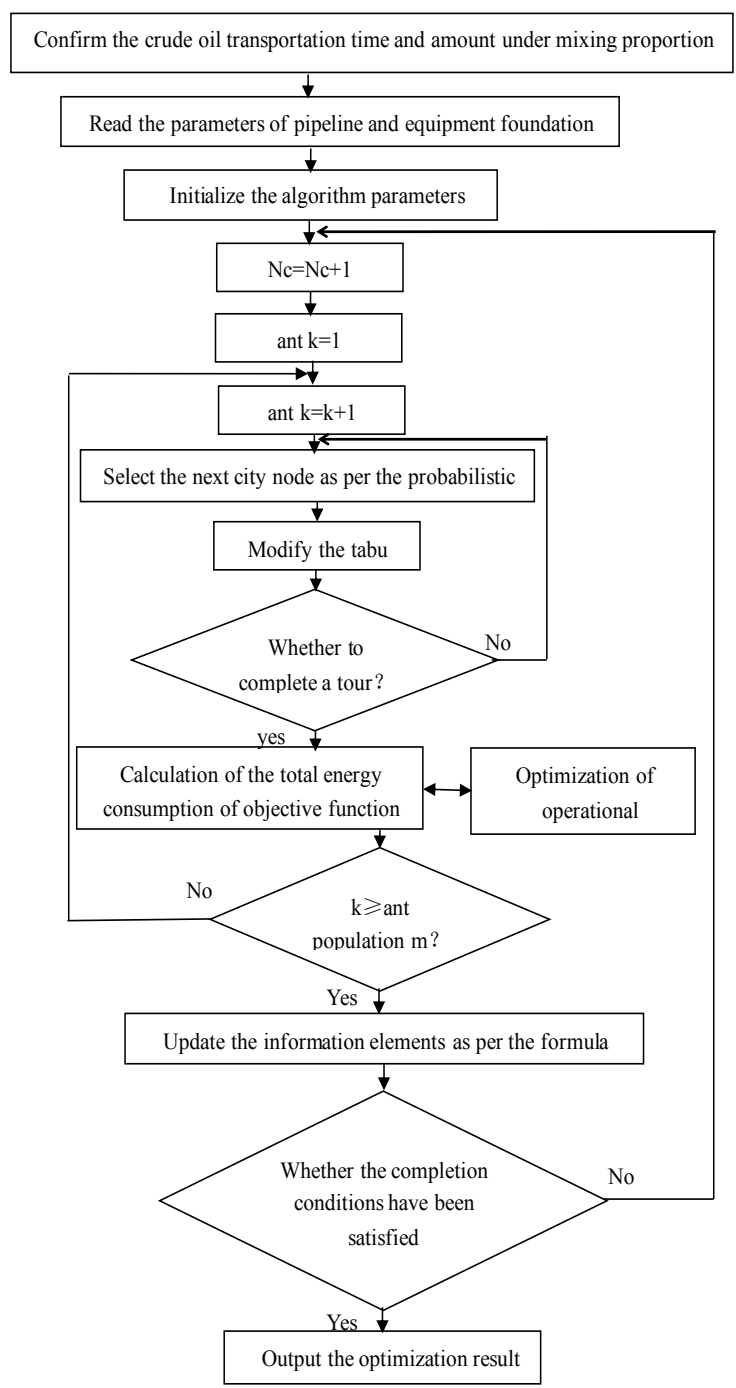

Fig. 1. Block Diagram of Algorithm Process

\section{Result Analysis and Discussion}

This study selects the production and operation program of the oil pipeline from Daqing Oilfield of CNPC to Harbin Refining and Chemical Factory as the optimization object. This pipeline was put into formal operation in November 2014. The crude oil in the pipeline is the crude oil mixed per certain ratio with the crude oil from Daqing Oilfield of CNPC and Russian crude oil. The pipeline is $199.73 \mathrm{~km}$ long in total with a pipe diameter of $\varphi 377 \times 6.3 \mathrm{~mm}$ and a buried depth of $1.5 \mathrm{~m}$. Along the entire line, the following four crude oil transportation stations are set up: the first station, the No. 1 middle station, No. 2 middle station, and the end station. Among which, the first and the No. 2 middle stations are equipped with pumps and heating furnaces, whereas the No.1 middle station is only equipped with one heating furnace. 
After optimization of the production and operational program of this pipeline in September 2015, the planned time of crude oil transportation is 30 days, the planned total amount of Russia-Daqing commingled crude oil is $204255 \mathrm{t}$, and the transportation proportion is $1: 3$. The temperature of Russian crude oil is $12.3{ }^{\circ} \mathrm{C}$ and that of the Daqing crude oil is $49.1{ }^{\circ} \mathrm{C}$.

\subsection{Optimization result of the production and operation program}

Figures 1 and 2 present the general operational program before and after optimization of the pipeline in September 2015 , respectively. The proportion and time of crude oil transported, equipment starting program, ex-station temperature, and pressure parameters have evidently been optimized. Before optimization, the crude oil transportation proportion scheduling program is $1: 3$, and the transportation time is 30 days. After optimization, the proportion is $1: 1$ with transportation time of 16 days, and the proportion is $0: 1$ (pure Daqing oil) with transportation time of 14 days. The starting program of pump does not considerably change. While transporting commingled crude oil with a mixed proportion of $1: 1,2 \#$ oil transfer pump is substituted by the 3\# oil transfer pump. While transporting the commingled crude oil with a mixed proportion of $0: 1$, the $1 \#$ Daqing and the 2\# Russia oil supply pumps are closed, the 2\# Daqing oil supply pump is open. The starting program of heating furnace is considerably adjusted. The condensation points of 1:1 commingled crude oil is low, and 16 days of continuous transportation without heating can be realized with the assistance of the initial oil temperature of the two kinds of crude oil until the oil is transported to the end station. Therefore, the heating furnace does not need to be opened in the transportation of 1:1 commingled crude oil. The $3 \#$ heating furnace at the first station is closed in the transportation of 0:1 commingled crude oil because the supply temperature of Daqing oil is high. Although the exstation oil temperature at each station slightly increased in transportation of $0: 1$ commingled crude oil after optimization, the ex-station temperature of $1: 1$ commingled crude oil considerably decreased. Therefore, the ex-station temperature considerably decreased as a whole. The exstation pressure of each station under the two kinds of mixed proportion slightly increased compared with that before optimization.

The ex-station temperature of each crude oil transportation station considerably decreased. The comparative situation of various kinds of energy consumption before and after optimization is shown in Table 3.

Table 1. General Operation Program before Optimization

\begin{tabular}{|c|c|c|c|c|c|c|c|c|}
\hline $\begin{array}{c}\text { Oil } \\
\text { transportation } \\
\text { proportion }\end{array}$ & $\begin{array}{l}\text { Delivery } \\
\text { time (day) }\end{array}$ & $\begin{array}{c}\text { Throughput } \\
\text { (t/d) }\end{array}$ & $\begin{array}{l}\text { Station } \\
\text { yard }\end{array}$ & $\begin{array}{c}\text { Transportation } \\
\text { pump: }\end{array}$ & $\begin{array}{l}\text { Oil supply } \\
\text { pump }\end{array}$ & $\begin{array}{l}\text { Heating } \\
\text { furnace }\end{array}$ & $\begin{array}{c}\text { Outlet } \\
\text { temperature } \\
\text { ( ) }\end{array}$ & $\begin{array}{c}\text { Ex-station } \\
\text { pressure } \\
\text { (MPa) }\end{array}$ \\
\hline \multirow{3}{*}{$\begin{array}{c}\text { Mixed } \\
\text { proportion of } \\
\text { Russian crude } \\
\text { oil and Daqing } \\
\text { crude oil is } 1: 3 \\
\text { Delivery }\end{array}$} & \multirow{3}{*}{30} & \multirow{3}{*}{6808.5} & $\begin{array}{c}\text { First } \\
\text { station }\end{array}$ & $2 \#$ & $\begin{array}{l}\text { 1\#Daqing } \\
\text { 2\#Russian }\end{array}$ & $3 \#$ & 41.7 & 4.67 \\
\hline & & & $\begin{array}{l}\text { No. } 1 \\
\text { middle } \\
\text { station }\end{array}$ & - & - & $2 \#$ & 41.4 & 3.08 \\
\hline & & & $\begin{array}{l}\text { No. } 2 \\
\text { middle } \\
\text { station }\end{array}$ & - & - & $1 \#$ & 42.1 & 1.46 \\
\hline
\end{tabular}

Table 2. General Operation Program after Optimization

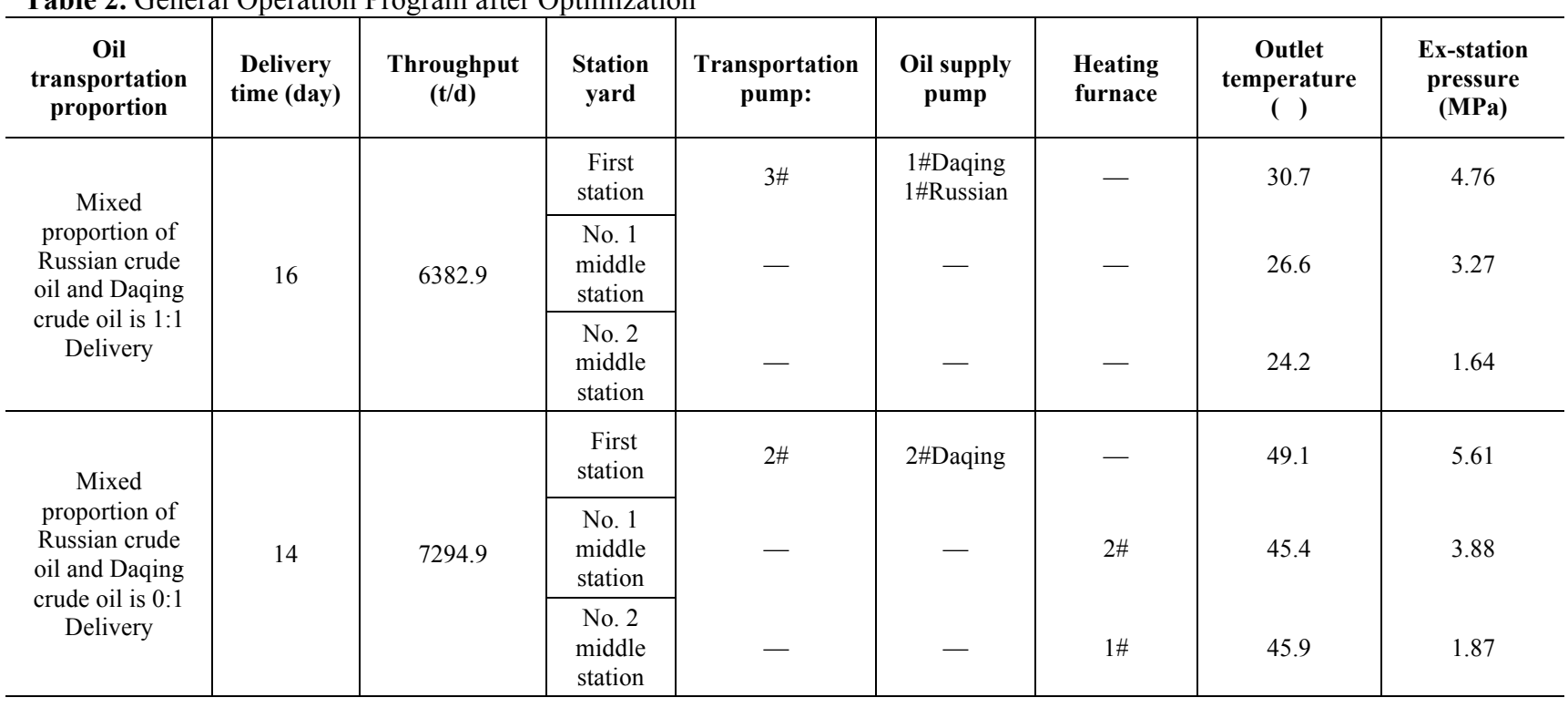

\subsection{Calculation of energy consumption of pipeline}

Table 3 compares the energy consumption before and after optimization of the pipeline in September, 2015. Although the consumption of electricity increased by $103,169 \mathrm{KWh}$ after optimization, the total consumption amount of fuel oil 
decreased by 155.6 t. Compared with the situation before optimization, the total energy consumption costs of crude oil transportation reduced by $\mathrm{RMB} 437,500$, thereby saving $26.28 \%$.

Table 3. Comparison of Energy Consumption before and after Optimization

\begin{tabular}{|c|c|c|c|c|c|c|}
\hline \multicolumn{2}{|c|}{$\begin{array}{c}\text { Total consumption amount of water } \\
\text { electricity (KWh) }\end{array}$} & \multicolumn{2}{|c|}{$\begin{array}{l}\text { Total consumption amount of fuel oil } \\
\text { (t) }\end{array}$} & \multicolumn{2}{|c|}{$\begin{array}{l}\text { Total costs of crude oil transportation } \\
\left(\mathrm{RMB}^{* 10,000)}\right. \\
\end{array}$} & \multirow{2}{*}{$\begin{array}{c}\text { Savings (\%) } \\
26.28\end{array}$} \\
\hline $\begin{array}{c}\text { Before } \\
\text { optimization } \\
758,595\end{array}$ & $\begin{array}{c}\text { After } \\
\text { optimization } \\
861,764\end{array}$ & $\begin{array}{c}\text { Before } \\
\text { optimization } \\
329.7\end{array}$ & $\begin{array}{c}\text { After optimization } \\
174.1\end{array}$ & $\begin{array}{c}\text { Before } \\
\text { optimization } \\
165.24\end{array}$ & $\begin{array}{c}\text { After optimization } \\
121.49\end{array}$ & \\
\hline
\end{tabular}

\section{Conclusions}

This study targeted the issue that crude oil transportation of commingled crude oil transportation pipeline with the same mixed proportion in different seasons could result in high energy consumption in crude oil transportation of the entire pipeline. Based on a comprehensive consideration of effects of equipment combination and operational parameters on energy consumption, this study included the proportion of oil transported and the oil transportation time corresponding to the mixed proportion of transportation into the variants of decision. The mathematical model of mixed transportation pipeline optimization was set up to target the minimum total energy consumption. Hierarchical solving was performed with the ant colony algorithm and the Powell direction acceleration method featuring the penalty function for the structural layer of the model. When the total crude oil throughput, initial temperature, and the mixed proportion of crude oil were given, this study carried out optimization research on the oil transportation proportion scheduling program, the equipment combination starting program, and the operational parameter program. The following conclusions are drawn:

(1) After optimization of the crude oil transportation proportion scheduling program and the equipment operational program under each oil transportation proportion, the operational situation of pump slightly changed, the number of heating furnace under various kinds of oil transportation proportion decreased, and the number of days commingled crude oil heating via opening the heating furnace considerably decreased. Under the 1:1 oil transportation proportion, the commingled crude oil can be continuously transported using the initial oil temperature without heating for 16 days until it is transported to the end station.

(2) After optimization of crude oil transportation proportion scheduling program and the pipeline operating parameters under each oil transportation proportion, the exstation pressure of each transportation station under each oil transportation proportion slightly increased compared with that before optimization, and the ex-station temperature of each oil transportation station significantly decreased.

(3) Compared with the situation before optimization, the power consumption after optimization significantly decreased, and the total energy consumption of crude oil transportation pipeline also decreased. Therefore, the energy saving effect of the pipeline production operational program after optimization of crude oil transportation proportion was apparent.

In summary, this study comprehensively considered the influence of different kinds of mixed proportion and the transportation time of pipeline crude oil transported on the optimization target function, confirmed the optimal oil transportation proportion program, the corresponding pump combination, and the optimal operational parameters within one period of crude oil transportation, and provided convenient and accurate technology support for the optimization of production and operation program under mixed transportation conditions on the crude oil transportation site.

However, a similar proportion of commingled crude oil leads to small physical properties. Limited by the physical property test precision of different proportions of commingled crude oil, taking a considerable amount of commingled crude oil as the study object is difficult. Consequently, a certain extent of gap exists between the optimized crude oil transportation proportion program and the actual optimal program. Therefore, testing additional kinds of physical properties of commingled crude oil with a similar proportion using accurate testers is beneficial to the optimized result accuracy of the production and operation program in the transportation process of different proportions of commingled crude oil of from Daqing Oilfield to Harbin Refining and Chemical Factory pipeline.

This is an Open Access article distributed under the terms of the Creative Commons Attribution Licence

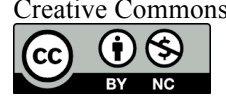

\section{References}

1.Wu, C. C., Yan, D. F., "Two levels of Optimal Model of Stable Operation of Hot Oil Pipeline". Acta Petrolei Sinica, 10(3), 1989, pp.109-115.

2. Wu, C. C., Yan, D. F., "Optimization of Operational Management of Hot Oil Pipeline”, Journal of Jianghang Petroleum Institute, 14(3) 1992, pp.83-88.

3. Modisette, J. P., "Minimizing fuel consumption of crude and products pipelines using continuous-state dynamic programming". In: Proceedings of the Biennial International Pipeline Conference, Alberta, Canada: American Society of Mechanical Engineers, 2007, pp.881-890.

4.Yong, T. R., Jefeerson, J. T., "Shell Pipeline Calls It Dynam Programming”. Oil\&Gas Journal, 59(19), 1961, pp. 8-12.
5.Vijerden, N. G., "Optimization Pipeline Operation", Journal of Petroleum Technology, 32(11),1980, pp. 2063-2067.

6.Linke, A. C., "Aided Computer Minimization of Crude Oil and Product Pipeline Transport Costs". Oil Gas European Magazine, 15(4), 1996, pp.56-58.

7. Nguyen, H. H., "Optimal scheduling of gas pipeline operation using genetic algorithms", In: Canadian Conference on Electrical and Computer Engineering, Sacaton., Canada: Institute of Electrical and Electronics Engineers Inc. 2005, pp.2195-2198.

8. Afshar, M. H., "Optimal operation of pipeline systems using genetic algorithm". In: IEEE Congress on Evolutionary Computation, Trondheim, Norway: IEEE Computer Society, 2009, pp.1399-1405. 
9. Chebouba, A., "Optimization of natural gas pipeline transportation using ant colony optimization". Computers and Operations Research, 2009, pp.1916-1923.

10. Sun, F. F., Yu, T., "Crude oil pipeline operation and optimization", In: International Conference on Pipelines and Trenchless Technology, Xiamen, China: American Society of Civil Engineers (ASCE), 2014, pp. 518-528.

11. Sun, Q. F., Wu Changchun., "Analysis on Optimal of Stable Operation of Daqing-Tieling Oil Pipeline System", Oil \& Gas Storage and Transportation, 23(6), 2004, pp. 7-14.

12. Li, Y. C., "Study on Safety Operation Technology of the Oil Pipeline of Hailaer Oil Field". Master thesis of Northeast Petroleum University, China,2011, pp. 25-87.

13. Chen, Y. W., Zuo, L. L., Lin, R., Zhu, Y. R., Wei, J. D., "Development and Application of Energy Consumption Measurement Software of Crude Oil Pipeline". Oil \& Gas Storage and Transportation, (05), 2013, pp. 499-503.
14. Sun, F. F., "Energy Conservation and Emission Reduction Practices of Western Crude Oil Pipeline". Oil \& Gas Storage and Transportation, (12), 2015, pp. 1295-1299.

15. Li, H. N., Wu, J. Y., Tao, J. H., Xu, L., Zhang, Z., "Research on Optimization of Oil Transportation Program of Crude Oil Pipeline under the Electricity Price Peak System". Natural Gas and Oil, (04), 2016, pp. 7-11+6.

16. Wei, L. X., Wang, Y., Zhang, L. Y., "Simulation of operation scheme of Su Cuo buried oil pipeline". Advanced Materials Research, 356(4), 2012, pp. 3023-3027.

17. Yu, Y., Wu, C. C., Xing, X. K., "Energy saving for a Chinese crude oil pipeline". In: Pressure Vessels and Piping Conference, California, USA: American Society of Mechanical Engineers (ASME), 2014. pp. $18-37$

18. Wang, Y. G., "A Study on Optimal Operation and Energy Saving of Super Heavy Oil Pipeline". In: International Conference on Computer Distributed Control and Intelligent Environmental Monitoring, Changsha, China: IEEE Computer Society, 2011, pp. 400-403. 